\title{
Fossil and Non-fossil Fuel Sources of Organic and Elemental Carbonaceous Aerosol in Beijing, Shanghai, and Guangzhou: Seasonal Carbon Source Variation
}

\author{
Di Liu', Matthias Vonwiller², Jun Li ${ }^{1 *}$, Junwen Liu³ ${ }^{3}$, Sönke Szidat², Yanlin Zhang4, \\ Chongguo Tian ${ }^{5}$, Yinjun Chen ${ }^{6}$, Zhineng Cheng', Guangcai Zhong ${ }^{1}$, Pingqing Fu ${ }^{7}$, Gan Zhang ${ }^{1}$
}

\author{
${ }^{1}$ State Key Laboratory of Organic Geochemistry and Guangdong province Key Laboratory of Environmental Protection \\ and Resources Utilization, Guangzhou Institute of Geochemistry, Chinese Academy of Sciences, Guangzhou 510640, \\ China \\ ${ }^{2}$ Department of Chemistry and Biochemistry \& Oeschger Centre for Climate Change Research, University of Bern, Berne \\ 3012, Switzerland \\ ${ }^{3}$ Institute for Environmental and Climate Research, Jinan University, Guangzhou 511443, China \\ ${ }^{4}$ Yale-NUIST Center on Atmospheric Environment, International Joint Laboratory on Climate and Environment Change \\ (ILCEC), Nanjing University of Information Science and Technology, Nanjing 210044, China \\ ${ }^{5}$ Key Laboratory of Coastal Environmental Processes and Ecological Remediation, Yantai Institute of Coastal Zone \\ Research, Chinese Academy of Sciences, Yantai 264003, China \\ ${ }^{6}$ State Key Laboratory of Pollution Control and Resources Reuse, Key Laboratory of Cities' Mitigation and Adaptation to \\ Climate Change, College of Environmental Science and Engineering, Tongji University, Shanghai 200092, China \\ ${ }^{7}$ Institute of Surface-Earth System Science, Tianjin University, Tianjin 300072, China
}

\begin{abstract}
We measured the radiocarbon isotope signals in various fractions of carbonaceous aerosols sampled across four seasons (Oct 2013-Jul 2014) in three megacities of China, viz., Beijing, Shanghai, and Guangzhou. The contributions of fossil fuel (FF) and non-fossil fuel (NF) to the carbonaceous aerosol were estimated based on the radiocarbon content in the organic carbon (OC), water-soluble organic carbon (WSOC), water-insoluble organic carbon (WIOC), and elemental carbon (EC). Although NF generated the primary share (>55\%) during autumn in all of the cities, the seasonal contributions of the sources differed by location during the rest of the year. During winter, FF emissions constituted the majority of the carbonaceous pollution (64\%) in Beijing, probably as a result of increased coal combustion for heating. On average, the EC, WSOC, and WIOC generated by FF composed $\sim 10 \%, 35 \%$, and $19 \%$ of the total carbon (TC). Overall, NF was identified as the largest source of carbonaceous aerosol in Guangzhou (63\%), whereas FF was the largest source, contributing slightly more than $\mathrm{NF}$, in Shanghai (54\%). During spring and summer, FF played a greater role than NF in Beijing ( $55 \%)$ and Guangzhou ( $63 \%)$; additionally, based on our limited number of samples, it contributed $71 \%$ in Shanghai during the latter season, with a significant portion due to fuel combustion (i.e., industrial, vehicular, fishing-boat, and large-vessel emissions).
\end{abstract}

Keywords: Carbonaceous aerosol; Fine aerosol; Source apportionment.

\section{INTRODUCTION}

Large-scale pollution of fine particles (aerodynamic diameter $\leq 2.5 \mu \mathrm{m} ; \mathrm{PM}_{2.5}$ ) occurs frequently, impacting air quality in the megacities of China due to massive and intensive pollutant emissions combined with unfavorable meteorological conditions. Among aerosol pollutants, carbonaceous aerosols, which can constitute $20-50 \%$ of

\footnotetext{
${ }^{*}$ Corresponding author.

Tel.: +86-20-85291508; Fax: +86-20-85290706

E-mail address: junli@gig.ac.cn
}

aerosols in the urban atmosphere (Cao et al., 2007), are of great concern due to their adverse impacts on air quality, visibility, human health and climate (Pratsinis et al., 1984; Highwood and Kinnersley, 2006; Mauderly and Chow, 2008). Carbonaceous materials are operationally classified as strongly refractory, highly polymerized carbon (elemental carbon [EC] or black carbon [BC]) and weakly refractory, light polycyclic or polyacidic hydrocarbon (organic carbon [OC]) (Castro et al., 1999; Pöschl, 2005). EC originates exclusively from primary sources and is emitted during incomplete combustion of fossil fuels (FFs; i.e., coal and petroleum) and biomass burning (BB; i.e., heating and wood fires). $\mathrm{OC}$ is a complex mixture of primary (directly emitted) OC (POC) and secondary OC (SOC) particles formed in situ 
in the atmosphere via oxidation of gas-phase precursors. Further sub-categories of OC, including water-soluble organic carbon (WSOC) and water-insoluble OC (WIOC), are distinguished on the basis of water solubility (Szidat et al., 2004). This classification may provide insight into assessment of different sources of OC, since WSOC is thought to be a good proxy for SOC in the absence of biomass burning (Weber et al., 2007), while WIOC is thought to be mainly from primary origins with a substantial contribution from fossil fuel emissions (Miyazaki et al., 2006). Using a recently developed method, source apportionment can be determined by measuring the radiocarbon $\left({ }^{14} \mathrm{C}\right)$ content of $\mathrm{OC}$ and $\mathrm{EC}$ separately, which enables unambiguous differentiation between FF and non-FF (NF) sources (Liu et al., 2013; Liu et al., 2014; Zhang et al., 2015a; Liu et al., 2016; Zong et al., 2016; Liu et al., 2017c). This differentiation is possible because ${ }^{14} \mathrm{C}$ is completely decayed in FF sources (i.e., diesel exhaust, gasoline exhaust and coal combustion), whereas $\mathrm{NF}$ sources (i.e., BB, cooking and biogenic emissions) exhibit contemporary ${ }^{14} \mathrm{C}$ levels (Szidat et al., 2009). Even more precise ${ }^{14} \mathrm{C}$-based source apportionment can be obtained by dividing OC into WSOC and WIOC (Liu et al., 201; Zong et al., 20166; Zhang et al., 2017).

Beijing, Shanghai, and Guangzhou are representative megacities located in different climatic regions (the BeijingTianjin-Hebei region, Yangtze River Delta region, and Pearl River Delta region, respectively) that suffer from severe air pollution due to rapid expansion of industry and transportation, sharply increasing the population and thus the demand for FFs (Ling et al., 2011; Feng et al., 2015; Zhang et al., 2015a; Ding et al., 2017; Wei et al., 2017). Although source apportionment of carbonaceous aerosols has been conducted in some cities (Liu et al., 2014; Elser et al., 2016; Liu et al., 2017c; Wei et al., 2017; Liu et al., 2018), the results are segmented and generally pertain to haze events during winter. In our previous research, several independent case studies were conducted in Guangzhou. For example, during winter (29 Nov 2012-19 Jan 2013), higher contributions of FF sources to EC (80-90\%) were observed for haze samples that were substantially impacted by local emissions, and lower contributions of FF to EC (60-70\%) were found for haze particles impacted by regional transport (Liu et al., 2014). During spring (15 Mar-15 Apr 2013), FF sources majorly contributed to total carbonaceous aerosols $(54 \pm 5 \%)$ (Liu et al., 2016). During summer (25 Jun-15 Jul 2013), $87 \%$ of EC and $53 \%$ of OC in $\mathrm{PM}_{2.5}$ were derived from FF sources on a typical summer day, but these values dropped significantly with invasion of NF-enriched air masses from rural and suburban areas (Liu et al., 2018). During autumn (15 Oct-15 Nov 2013), NF was the predominant source of total carbon (TC; average $=65 \pm 7 \%$ ) (Liu et al., 2017a). There are still a few studies with regard to comprehensive ${ }^{14} \mathrm{C}$ measurement of $\mathrm{OC}$ and $\mathrm{EC}$ on seasonal scale. In this study, a $\mathrm{PM}_{2.5}$ sampling campaign was conducted simultaneously in three cities over 1 year, and two samples with relatively high and low $\mathrm{PM}_{2.5}$ concentrations during each season in the three cities were selected for ${ }^{14} \mathrm{C}$ analysis. ${ }^{14} \mathrm{C}$ data of ambient aerosols from Beijing, Shanghai, and Guangzhou are presented for these two sub-fractions in terms of TC, OC and EC. Furthermore, OC was divided into water-insoluble OC and water-soluble OC. A comparison of the sources and seasonal variation of carbonaceous aerosols among the three cities was conducted. The results can help identify the carbon sources of aerosols in China and support policymakers in developing appropriate air quality management initiatives for particulate matter pollution.

\section{METHODS}

\section{Aerosol Sampling}

$\mathrm{PM}_{2.5}$ samples were collected in Beijing, Shanghai, and Guangzhou during the four seasons. Detailed descriptions of the sampling sites, sampling methods and protocols have been described previously (Liu et al., 2017a). Briefly, four sampling periods were selected to represent the four seasons: autumn ( $\mathrm{n}=83,16$ Oct-15 Nov 2013), winter $(\mathrm{n}=80,20$ Dec 2013-20 Jan 2014), spring ( $\mathrm{n}=82,20 \mathrm{Mar}-20 \mathrm{Apr}$ 2014), and summer ( $\mathrm{n}=81,20$ Jun-20 Jul 2014). During each season, 24-h-integrated $\mathrm{PM}_{2.5}$ samples were collected on pre-heated $\left(450^{\circ} \mathrm{C}\right.$ for $\left.5 \mathrm{~h}\right)$ quartz fiber filters $(8 \times 10$ in.; Whatman, UK, or Pall, USA) using a high-volume sampler (Shanghai Xintuo) at a flow rate of $0.3 \mathrm{~m}^{3} \mathrm{~min}^{-1}$. In this study, we collected 110, 110, and 106 samples from Beijing, Shanghai, and Guangzhou, respectively. At each sampling site and season, one field blank sample was collected and analyzed. All samples were stored at $-20^{\circ} \mathrm{C}$ until analysis. Two filter samples of low and high $\mathrm{PM}_{2.5}$ loading at each site with the same wind direction and wind field were chosen for ${ }^{14} \mathrm{C}$ measurement although sample size was limited.

\section{Thermal-Optical Carbon Analysis}

Portions of the filter samples $\left(1.5 \mathrm{~cm}^{2}\right)$ were cut for analysis of the OC and EC content (OC/EC) using a thermaloptical carbon analyzer (Sunset Laboratory Inc., Forest Grove, OR, USA) following a modified National Institute of Occupational Safety and Health (NIOSH) thermal-optical transmission protocol. Both the NIOSH thermal-optical transmission protocol and the Interagency Monitoring of Protected Visual Environments (IMPROVE) thermal-optical reflectance protocol are common thermal-optical methods. Due to differences in charring correction and the temperature program, the NIOSH-defined EC concentration was slightly lower than that defined by IMPROVE, although the TC concentrations measured by the two methods were comparable (Cheng et al., 2011). Replicate samples and a filter blank were conducted to determine the analytical precision and identify background contamination. Analysis of replicate samples $(n=6)$ provided good analytical precision, with relative deviations of $4.5 \%, 8.6 \%$ and $4.5 \%$ for OC, EC and $\mathrm{TC}$, respectively. The average field blank concentration of OC was $1.47 \pm 0.17 \mu \mathrm{g} \mathrm{cm}^{-2}(1 \sigma, \mathrm{n}=12)$, and that of EC was undetectable. The lowest $\mathrm{OC}$ value observed on a filter was $\sim 10 \mu \mathrm{g} \mathrm{cm}^{-2}$ before subtraction of the blank value. The reported OC concentrations were adjusted by subtraction of the values of the filter blanks.

\section{${ }^{14}$ C Analysis of the Carbonaceous Fractions}

${ }^{14} \mathrm{C}$ was measured in carbonaceous aerosols to distinguish 
FF and NF sources quantitatively. Two samples with relatively high and low $\mathrm{PM}_{2.5}$ concentrations collected in each season and city were selected for ${ }^{14} \mathrm{C}$ analysis, although only one sample was analyzed during summer in Shanghai (23 samples total). The 3-day air mass back trajectories for all selected samples are shown in Fig. 1.

The detailed separation method of $\mathrm{OC}$ and $\mathrm{EC}$ for ${ }^{14} \mathrm{C}$ measurement has been provided in previous studies (Zhang et al., 2012, 2015a). In brief, the ${ }^{14} \mathrm{C}$ content of different carbon fraction was analyzed through coupling of an elemental analyzer with a Mini Carbon Dating System (MICADAS) at the University of Bern, Switzerland (Szidat et al., 2014). Each filter punches $\left(\sim 4 \mathrm{~cm}^{2}\right)$ was extracted using $20 \mathrm{~mL}$ ultrapure water with low TOC impurity $(<3 \mathrm{ppb})$ to remove WSOC. The filter punch was then removed and placed in the desiccator for drying before the ${ }^{14} \mathrm{C}$ measurements were taken. ${ }^{14} \mathrm{C}$ analysis of $\mathrm{EC}$ and WIOC were carried out through online coupling of the MICADAS with a Sunset $\mathrm{Lab} \mathrm{OC} / \mathrm{EC}$ analyzer, and the $\mathrm{CO}_{2}$ resulting from $\mathrm{EC}$ or WIOC was separated during either the EC or OC step of the Swiss_4S protocol (Zhang et al., 2012; Agrios et al., 2015). The ${ }^{14} \mathrm{C}$ analysis results were expressed as fractions of modern carbon $\left(f_{M}\right)$ and is referenced to the ratio ${ }^{14} \mathrm{C} /{ }^{12} \mathrm{C}$ in atmospheric $\mathrm{CO}_{2}$ in the year 1950 (Stuiver and Polach, 1977). The $f_{M}$ values for OC were not measured directly but were deduced through subtraction of TC and EC based on mass balancing. Similarly, $f_{M}$ values of WSOC were further calculated via mass balancing through subtraction of $\mathrm{OC}$ and WIOC. The average uncertainties of $\mathrm{f}_{\mathrm{M}}$ values for OC, EC, TC and WSOC were $<10 \%$, including uncertainties from ${ }^{14} \mathrm{C}$ measurements, blank correction and mass-balance calculations. In order to correct excess ${ }^{14} \mathrm{C}$ from nuclear bomb tests in the $1950 \mathrm{~s}$ and $1960 \mathrm{~s}, \mathrm{f}_{\mathrm{M}}$ were then converted to the fraction of contemporary carbon $\left(f_{c}\right)$ (Stuiver and Polach, 1977). The detailed calculation method of the separation of fossil and non-fossil carbon species in each carbonaceous fraction can be found in the previous paper (Liu et al., 2016) and is displayed in the supplementary material.

\section{RESULTS AND DISCUSSION}

\section{Seasonal Variation and Concentrations of PM2.5, OC and EC}

Fig. 2 shows box-and-whisker plots for the concentrations of $\mathrm{PM}_{2.5}, \mathrm{OC}$ and $\mathrm{EC}$ and $\mathrm{EC} / \mathrm{OC}$ ratios during the sampling campaign at all three sites. The average $\mathrm{PM}_{2.5}$ mass concentrations in Beijing, Shanghai, and Guangzhou were 182 $\pm 78.3 \mu \mathrm{g} \mathrm{m}^{-3}, 88.6 \pm 49.4 \mu \mathrm{g} \mathrm{m}^{-3}$, and $80.4 \pm 30.7 \mu \mathrm{g} \mathrm{m}^{-3}$, respectively. Despite large variations in the $\mathrm{PM}_{2.5}$ levels observed at all sites, concentrations were generally higher in Beijing than in Shanghai or Guangzhou. This result indicates poorer air quality in northern China, which is consistent with previous studies (Hu et al., 2014).

On average, the highest concentrations of OC and EC in $\mathrm{PM}_{2.5}$ were observed in Beijing $\left(21.1 \pm 13.9 \mu \mathrm{g} \mathrm{m}^{-3}\right.$ and 2.8 $\left.\pm 2.2 \mu \mathrm{g} \mathrm{m}^{-3}\right)$, followed by Guangzhou $\left(17.3 \pm 9.6 \mu \mathrm{g} \mathrm{m}^{-3}\right.$ and $\left.2.9 \pm 1.3 \mu \mathrm{g} \mathrm{m}^{-3}\right)$ and Shanghai $\left(9.0 \pm 7.6 \mu \mathrm{g} \mathrm{m}^{-3}\right.$ and $\left.1.6 \pm 1.5 \mu \mathrm{g} \mathrm{m}^{-3}\right)$. To convert OC to organic matter $(\mathrm{OM}) \mathrm{a}$ conversion factor of 1.6 is used based on site type (Turpin and Lim, 2001). The percentages of TC matter (TCM $=1.6$

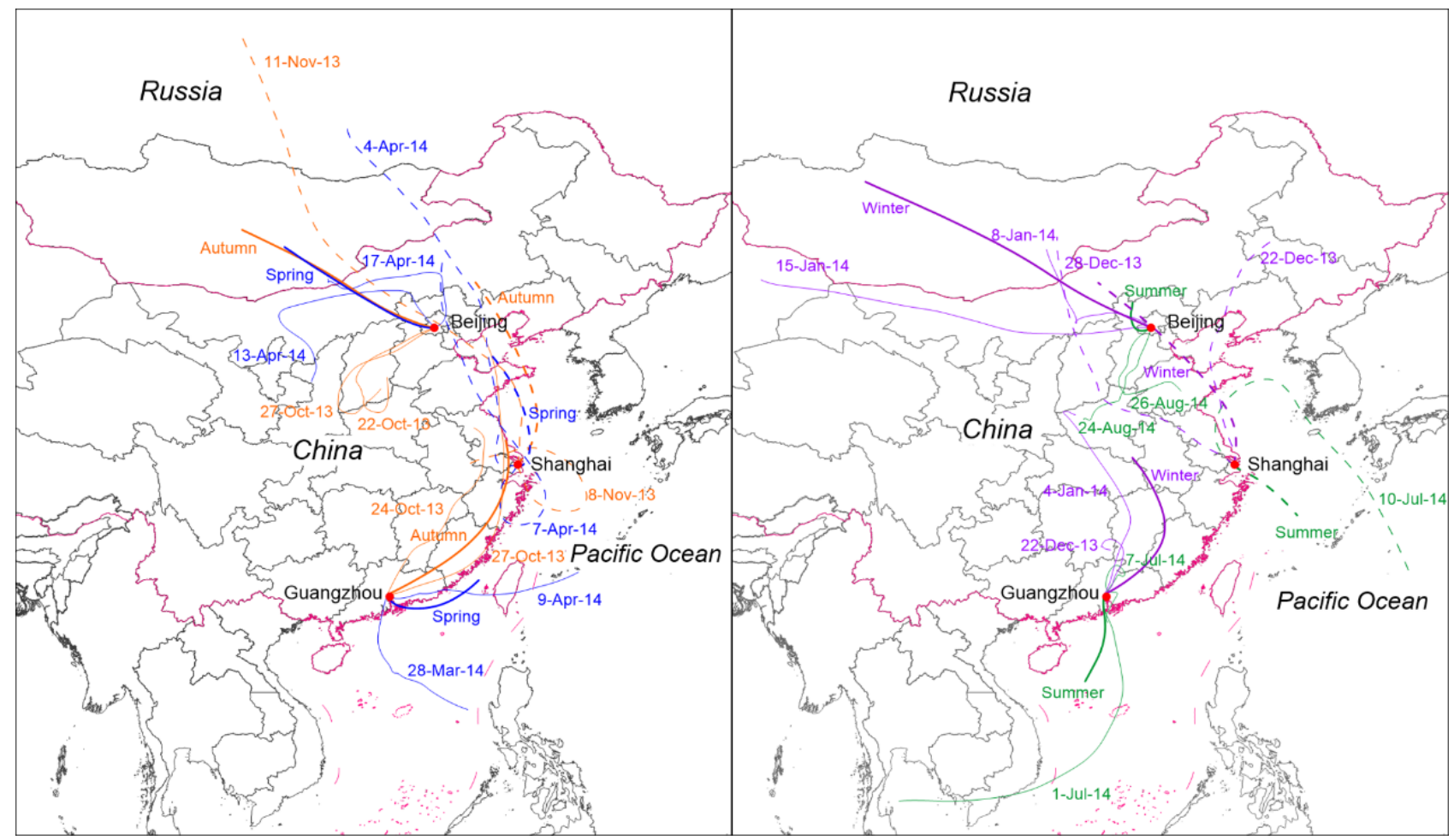

Fig. 1. 3-day back trajectories of air mass with $6 \mathrm{~h}$ intervals modeled at $500 \mathrm{~m}$ above ground level by Air Resources Laboratory, National Oceanic and Atmospheric Administration (http://ready.arl.noaa.gov/HYSPLIT.php). Starting time of trajectories are at 0:00 UTC for Beijing, Shanghai and Guangzhou. 

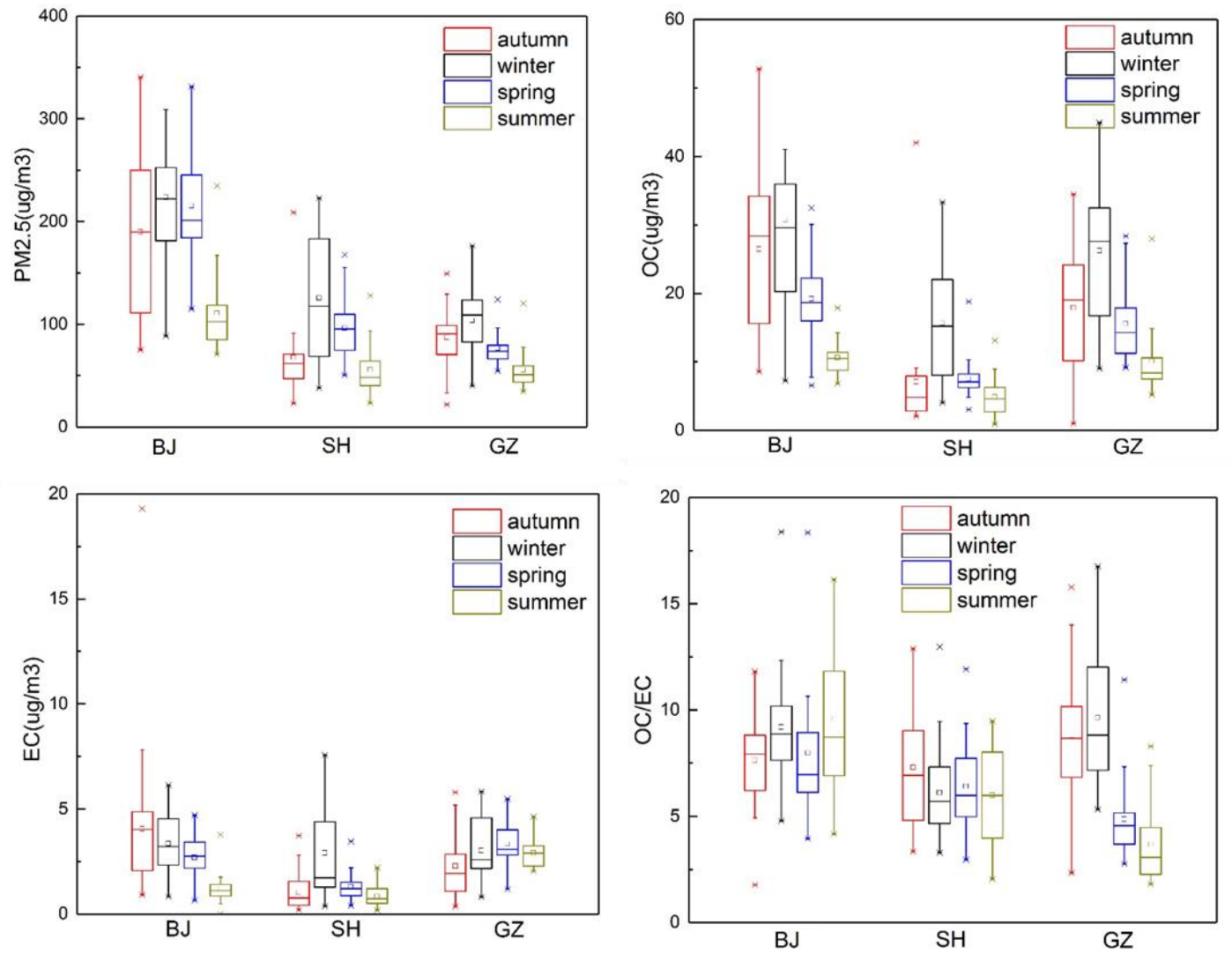

Fig. 2. Box-and-whisker plots of mass concentrations of $\mathrm{PM}_{2.5}, \mathrm{OC}, \mathrm{EC}$ and EC/OC ratios in Beijing (BJ, total 110 samples), Shanghai (SH, total 110 samples) and Guangzhou (GZ, total 105 samples) during sampling periods 2013-2014. The box represents the $25^{\text {th }}$ (lower line), $50^{\text {th }}$ (middle line) and $75^{\text {th }}$ (top line) percentiles values, while the end of the lower and upper vertical line represents the $10^{\text {th }}$ and $90^{\text {th }}$ percentile values, respectively.

$\times \mathrm{OC}+\mathrm{EC})$ to total fine particle mass were $20 \pm 6 \%, 17 \pm$ $6 \%$, and $36 \pm 8 \%$ in Beijing, Shanghai, and Guangzhou, respectively, indicating the importance of carbonaceous aerosols in air quality, especially in Guangzhou in southern China. However, no significant correlations were found between the ratio of TCM/PM ${ }_{2.5}$ and $\mathrm{PM}_{2.5}$ concentration in Beijing and Shanghai, indicating that carbonaceous aerosols are the major component of $\mathrm{PM}_{2.5}$ but did not play a predominant role when $\mathrm{PM}_{2.5}$ concentrations were higher. On the other hand, in Guangzhou, the ratio of TCM/PM 2.5 was positively correlated with the $\mathrm{PM}_{2.5}$ concentration $(\mathrm{R}=0.89$, $\mathrm{p}<0.05)$. This finding shows that the relative contributions of carbonaceous aerosols to total fine particles increased with increasing $\mathrm{PM}_{2.5}$ concentrations in Guangzhou, implying that the role of carbonaceous aerosols in $\mathrm{PM}_{2.5}$ is greater in southern China than in other parts of China. The average concentrations of $\mathrm{OC}$ and EC in Beijing, Shanghai, and Guangzhou in this study were similar to those reported in the same respective cities in $2013\left(38.6 \mu \mathrm{g} \mathrm{m}^{-3}\right.$ and $5.83 \mu \mathrm{g} \mathrm{m}^{-3}$, respectively, in Beijing; $10.9 \mu \mathrm{g} \mathrm{m}^{-3}$ and $3.03 \mu \mathrm{g} \mathrm{m}^{-3}$ in Shanghai; $14.4 \mu^{-3} \mathrm{~g} \mathrm{~m}^{-3}$ and $3.87 \mu \mathrm{g} \mathrm{m}^{-3}$ in Guangzhou) (Ding et al., 2016) but were significantly higher than those in European urban cities such as Athens, Greece $\left(2.1 \pm 1.3 \mu \mathrm{g} \mathrm{m}^{-3}\right.$ and $0.54 \pm 0.39{\mu \mathrm{g} \mathrm{m}^{-3}}^{-3}$ (Paraskevopoulou et al., 2014), and Elche, Spain $\left(5.6 \pm 2.8 \mu \mathrm{g} \mathrm{m}^{-3}\right.$ and $1.5 \pm 1.2 \mu \mathrm{g} \mathrm{m}^{-3}$ ) (Perrone et al., 2011), and in other Asian urban cities such as Seoul,
Korea $\left(10.2 \pm 5.5 \mu \mathrm{g} \mathrm{m}^{-3}\right.$ and $\left.4.1 \pm 2.6 \mu \mathrm{g} \mathrm{m}^{-3}\right)($ Kim et al., 2007), and Yokohama, Japan $\left(3.75 \pm 1.5 \mu \mathrm{g} \mathrm{m}^{-3}\right.$ and $1.94 \pm$ $1.2 \mu \mathrm{g} \mathrm{m}^{-3}$ ) (Khan et al., 2010).

The seasonal variations of $\mathrm{PM}_{2.5}$, $\mathrm{OC}$ and $\mathrm{EC}$ were characterized by mass concentrations that were higher during winter and lower during summer (Fig. 2). The high winter concentrations can be attributed mainly to a combination of complex effects, such as increasing emissions from local and regional coal and biomass or biofuel combustion and the associated secondary formation processes, as well as unfavorable meteorological conditions for pollution dispersal (Huang et al., 2014). Conversely, the low mass concentrations during summer are likely due to a sharp decrease in anthropogenic source emissions (i.e., heating-related coal and biofuel burning), relatively high wet-scavenging effects and a high mixing layer (Zhang et al., 2017).

Generally, the relationship between $\mathrm{OC}$ and $\mathrm{EC}$ can give some indication of the origin of carbonaceous particles. A strong relationship between OC and EC might indicate that the carbonaceous particles are derived from the same emission source. Lower OC/EC ratios (1.0-4.2) imply sources from diesel- and gasoline-powered vehicular exhaust (Schauer et al., 1999, 2002), whereas aerosols with higher OC/EC ratios might originate from coal combustion (Zhi et al., 2008), wood combustion (16.8-40.0) (Schauer et al., 2001), forest fires (14.5) (Zhang et al., 2007), BB (7.7) (Zhang et al., 2007) 
or formation of SOC (Chow et al., 1993). The correlations between OC and EC were higher in Beijing and Shanghai $(\mathrm{R}=0.93$ and 0.95 , respectively, and $\mathrm{p}<0.05)$ than in Guangzhou $(\mathrm{R}=0.62, \mathrm{p}<0.05)$. Moreover, the correlations of $\mathrm{OC}$ with $\mathrm{EC}$ and the $\mathrm{OC} / \mathrm{EC}$ ratio during different seasons in Beijing and Shanghai were generally consistent. This consistency implies that the sources of the carbonaceous aerosols in Beijing did not change drastically, and that these aerosols were derived from various mixtures. This characteristic was also observed in Shanghai, although the sources of the carbonaceous aerosols differed between the two cities. In Guangzhou, higher correlations between OC and EC during autumn $(\mathrm{R}=0.84, \mathrm{p}<0.05)$ and winter $(\mathrm{R}=$ $0.71, \mathrm{p}<0.05)$ were found, with a lower correlation during spring $(\mathrm{R}=0.62, \mathrm{p}<0.05)$ and no significant correlation during summer. The average OC/EC ratios were significantly higher $(\mathrm{p}<0.01)$ during autumn (8.6) and winter (9.6) than spring (4.9) and summer (3.7) (Fig. 2). This finding suggests that the major sources of carbonaceous aerosols differed markedly during different seasons in Guangzhou. Southern China is strongly influenced by anthropogenic emissions from the upwind Asian continent. Analysis of 3-day back trajectories showed that seasonal variations of carbonaceous aerosols were consistent with alteration of the winter and summer monsoons (Fig. 1); therefore, the major sources of carbonaceous aerosols originated from inland China during autumn and winter but from the Pearl River Delta during spring and summer. This difference in sources likely contributes to the significant seasonal differences in carbonaceous aerosols, which may be elucidated by the ${ }^{14} \mathrm{C}$ results.

\section{Seasonal Variation of ${ }^{14} \mathrm{C}$ Content}

The concentrations of different carbon species and their ratios in selected samples from three cities are listed in Table 1, and the proportion (\%) of FF sources in various carbon fractions of the corresponding samples are shown in Table 2. Overall, FF sources accounted for slightly greater contributions to TC in the three cities annually (average: $53 \pm 10 \%$; range: $31-71 \%$ ) than those of NF sources (average: $47 \pm 10 \%$; range: $29-69 \%$ ), and the values in all three cities were similar. For example, the FF:NF ratios in Beijing, Shanghai, and Guangzhou were 54:46, 53:47 and 52:48, respectively. Despite the wide range of EC concentrations (Table 1), the ratios of fossil $\mathrm{EC}\left(\mathrm{EC}_{\mathrm{f}}\right)$ to total $\mathrm{EC}$ in Beijing, Shanghai, and Guangzhou were comparable, with averages of $73 \pm$ $6 \%, 72 \pm 6 \%$, and $74 \pm 14 \%$, respectively, suggesting that FF combustion is the dominant contributor to EC. The high annual contribution of FFs to EC in the three cities was consistent with previous reports based on a similar ${ }^{14} \mathrm{C}$-based approach for analyzing EC in cities in China, including Beijing (79\% and $82 \%$ ) (Zhang et al., 2015a, b), Xi' an (78 $\pm 3 \%$ ) (Zhang et al., 2015a), Shanghai (79\%) (Zhang et al., 2015a), and Guangzhou (80-90\%) (Liu et al., 2014), as well as previous studies conducted in other cities around the world (Bernardoni et al., 2013; Liu et al., 2013; Andersson et al., 2015). The average contributions of fossil $\mathrm{OC}\left(\mathrm{OC}_{\mathrm{f}}\right)$ to OC were $50 \pm 10 \%, 49 \pm 9 \%$, and $45 \pm 10 \%$ in Beijing, Shanghai, and Guangzhou, respectively, which were lower

Table 1. Concentrations $\left(\mu \mathrm{g} \mathrm{C} \mathrm{m}^{-3}\right)$ of different carbon species and their ratios.

\begin{tabular}{|c|c|c|c|c|c|c|c|c|}
\hline Site & $\mathrm{PM}_{2.5}$ & WSOC & WIOC & $\mathrm{EC}$ & $\mathrm{OC}$ & TC & $\mathrm{OC} / \mathrm{EC}$ & $\mathrm{TC} \mathrm{PM}_{2.5}$ \\
\hline \multicolumn{9}{|l|}{ Beijing } \\
\hline 24-Oct-13 & 89.1 & 5.23 & 5.28 & 2.23 & 10.5 & 12.7 & 4.71 & 0.14 \\
\hline 27-Oct-13 & 326 & 43.8 & 26.9 & 18.2 & 70.7 & 89.0 & 3.88 & 0.27 \\
\hline 8-Jan-14 & 97.0 & 3.61 & 2.60 & 1.12 & 6.21 & 7.33 & 5.56 & 0.08 \\
\hline 15-Jan-14 & 518 & 98.3 & 48.9 & 19.7 & 147 & 167 & 7.49 & 0.32 \\
\hline 13-Apr-14 & 326 & 11.4 & 12.2 & 5.92 & 23.6 & 29.5 & 3.98 & 0.09 \\
\hline 17-Apr-14 & 176 & 14.1 & 6.28 & 5.39 & 20.4 & 25.7 & 3.78 & 0.15 \\
\hline 24-Aug-14 & 96.0 & 4.40 & 3.60 & 1.77 & 8.00 & 9.77 & 4.52 & 0.10 \\
\hline 26-Aug-14 & 103 & 3.71 & 3.48 & 2.20 & 7.19 & 9.39 & 3.28 & 0.09 \\
\hline \multicolumn{9}{|l|}{ Shanghai } \\
\hline 8-Nov-13 & 176 & 9.56 & 20.6 & 7.49 & 30.1 & 37.6 & 4.02 & 0.21 \\
\hline 11-Nov-13 & 67.2 & 1.88 & 2.56 & 1.02 & 4.44 & 5.46 & 4.37 & 0.08 \\
\hline 22-Dec-13 & 81.8 & 4.16 & 5.07 & 2.82 & 9.23 & 12.1 & 3.27 & 0.15 \\
\hline 28-Dec-13 & 216 & 9.51 & 17.2 & 9.73 & 26.7 & 36.4 & 2.75 & 0.17 \\
\hline 4-Apr-14 & 168 & 5.37 & 9.77 & 4.59 & 15.1 & 19.7 & 3.30 & 0.12 \\
\hline 7-Apr-14 & 110 & 4.63 & 4.19 & 2.20 & 8.81 & 11.0 & 4.00 & 0.10 \\
\hline 10-Jul-14 & 128 & 6.25 & 5.72 & 3.49 & 12.0 & 15.5 & 3.43 & 0.12 \\
\hline \multicolumn{9}{|l|}{ Guangzhou } \\
\hline 22-Oct-13 & 79.3 & 9.09 & 7.41 & 3.62 & 16.5 & 20.1 & 4.56 & 0.25 \\
\hline 27-Oct-13 & 124 & 8.79 & 14.0 & 5.80 & 22.8 & 28.6 & 3.93 & 0.23 \\
\hline 22-Dec-13 & 40.1 & 4.90 & 2.92 & 1.73 & 7.83 & 9.56 & 4.51 & 0.24 \\
\hline 4-Jan-14 & 159 & 48.9 & 20.4 & 8.04 & 69.2 & 77.3 & 8.61 & 0.49 \\
\hline 28-Mar-14 & 61.0 & 10.3 & 6.06 & 5.98 & 16.4 & 22.3 & 2.74 & 0.37 \\
\hline 9-Apr-14 & 124 & 23.3 & 13.2 & 13.5 & 36.4 & 50.0 & 2.69 & 0.40 \\
\hline 1-Jul-14 & 34.5 & 2.07 & 2.90 & 2.70 & 4.97 & 7.66 & 1.84 & 0.22 \\
\hline 7-Jul-14 & 120 & 11.7 & 11.8 & 8.09 & 23.5 & 31.6 & 2.90 & 0.26 \\
\hline
\end{tabular}


Table 2. Relative contribution of fossil fuel sources to different carbon fractions.

\begin{tabular}{|c|c|c|c|c|c|}
\hline Site/Time & WSOC & WIOC & $\mathrm{EC}$ & $\mathrm{OC}$ & $\mathrm{TC}$ \\
\hline \multicolumn{6}{|l|}{ Beijing } \\
\hline 24-Oct-13 & 0.37 & 0.33 & 0.67 & 0.35 & 0.41 \\
\hline 27-Oct-13 & 0.40 & 0.39 & 0.63 & 0.39 & 0.44 \\
\hline 8-Jan-14 & 0.63 & 0.49 & 0.72 & 0.57 & 0.60 \\
\hline 15-Jan-14 & 0.65 & 0.74 & 0.77 & 0.68 & 0.69 \\
\hline 13-Apr-14 & 0.56 & 0.44 & 0.75 & 0.50 & 0.55 \\
\hline 17-Apr-14 & 0.51 & 0.48 & 0.75 & 0.50 & 0.55 \\
\hline 24-Aug-14 & 0.45 & 0.43 & 0.77 & 0.44 & 0.50 \\
\hline 26-Aug-14 & 0.56 & 0.49 & 0.79 & 0.53 & 0.59 \\
\hline \multicolumn{6}{|l|}{ Shanghai } \\
\hline 8-Nov-13 & 0.23 & 0.40 & 0.67 & 0.35 & 0.41 \\
\hline 11-Nov-13 & 0.37 & 0.36 & 0.75 & 0.37 & 0.44 \\
\hline 22-Dec-13 & 0.45 & 0.54 & 0.72 & 0.50 & 0.55 \\
\hline 28-Dec-13 & 0.44 & 0.50 & 0.68 & 0.48 & 0.53 \\
\hline 4-Apr-14 & 0.44 & 0.53 & 0.71 & 0.50 & 0.55 \\
\hline 7-Apr-14 & 0.38 & 0.48 & 0.70 & 0.43 & 0.48 \\
\hline 10-Jul-14 & 0.69 & 0.67 & 0.84 & 0.68 & 0.71 \\
\hline \multicolumn{6}{|l|}{ Guangzhou } \\
\hline 22-Oct-13 & 0.35 & 0.44 & 0.67 & 0.39 & 0.44 \\
\hline 27-Oct-13 & 0.47 & 0.36 & 0.70 & 0.40 & 0.46 \\
\hline 22-Dec-13 & 0.35 & 0.44 & 0.61 & 0.38 & 0.42 \\
\hline 4-Jan-14 & 0.29 & 0.28 & 0.52 & 0.28 & 0.31 \\
\hline 28-Mar-14 & 0.52 & 0.57 & 0.84 & 0.54 & 0.62 \\
\hline 9-Apr-14 & 0.57 & 0.59 & 0.88 & 0.58 & 0.66 \\
\hline 1-Jul-14 & 0.54 & 0.53 & 0.86 & 0.54 & 0.65 \\
\hline 7-Jul-14 & 0.49 & 0.50 & 0.86 & 0.50 & 0.59 \\
\hline
\end{tabular}

than the corresponding $\mathrm{EC}_{\mathrm{f}}$ contributions in all samples. The high proportion of $\mathrm{OC}_{\mathrm{f}}(32-72 \%)$ indicated that primary emissions and secondary formation from NF sources (i.e., $\mathrm{BB}$ and biogenic emissions) are important contributors to OC in densely populated urbanized areas of China. This conclusion is also applicable to the outflow area of Shanghai (Miyakawa et al., 2019). However, more studies in the outflow areas of other big cities are needed to generalize this conclusion.

The relative contributions of FF and NF sources to EC, WIOC and WSOC in each of the four seasons are plotted in Fig. 3. Distinct seasonal patterns were found in the three cities. Generally, relatively high contributions of NF sources (54-59\%) to TC were found during autumn (late October to early November). Particulate EC was predominantly derived from the combustion of FFs (i.e., coal, gasoline and diesel) and NF sources (i.e., burning of vegetation and wood). In this study, the proportion of EC derived primarily from BB was also higher during autumn (> 30\%) than during the other seasons. Biomass burning of agricultural waste (i.e., straw burning) has been suggested to have a strong impact on primary carbonaceous aerosol in Beijing (Xu et al., 2018; Zha et al., 2013). Large contribution of EC from biomass burning was observed during this season in/around Beijing (Liu et al., 2017a).

During winter, the carbon source compositions of the cities differed. The percentage of FF-derived sources was increased significantly in Beijing. $\mathrm{WIOC}_{\mathrm{f}}$ and $\mathrm{EC}_{\mathrm{f}}$ were generally considered to be primary emissions from fossil fuel source (i.e., coal combustion and vehicle exhaust) (Miyazaki et al., 2006; Dusek et al., 2017). Generally, the $\mathrm{WIOC}_{\mathrm{f}} / \mathrm{EC}_{\mathrm{f}}$ ratios of coal combustion (2.7-6.1) were higher than those of vehicle emissions (0.5-1.3) (He et al., 2008; Zhang et al., 2008; Zhou et al., 2014). The highest $\mathrm{WIOC}_{\mathrm{f}} / \mathrm{EC}_{\mathrm{f}}$ ratio in this study (2.39) was obtained in Beijing during winter; this suggests that the increase in the FF-derived contribution was associated with increasing emissions from coal combustion for heating purposes during the cold season in northern China (Fig. 1), which was confirmed by the aerosol mass spectrometer measurements obtained during the same season (Elser et al., 2016). Based on another study, this FF source enhancement might be attributed to residential coal combustion (Liu et al., 2017c). In Shanghai, the contribution of fossil carbon increased approximately $11 \%$. The $\mathrm{WIOC}_{\mathrm{f}} / \mathrm{EC}_{\mathrm{f}}$ ratio of 1.3 indicated that the FF-derived carbon source was more likely from vehicle emissions. In Guangzhou, the contribution of NF sources was the highest $(69 \%)$, and the $\mathrm{EC}_{\mathrm{bb}} / \mathrm{EC}$ ratio reached 0.39 and 0.48 in winter samples. As shown in Fig. 1, air masses arrived from the north of Guangdong, Hunan and Guizhou Provinces, where a large amount of biomass, including agricultural waste and hard wood, was burned for cooking and domestic heating during the cold, dry winter (Jiang et al., 2018). This carbon source characterization matches that reported for regional-scale haze events in a previous study (Liu et al., 2014).

Source composition of carbonaceous aerosol (OC and EC) was characterized as higher contributions from fossil source, accounting for $55 \%, 54 \%$, and $52 \%$ of TC for Beijing, 

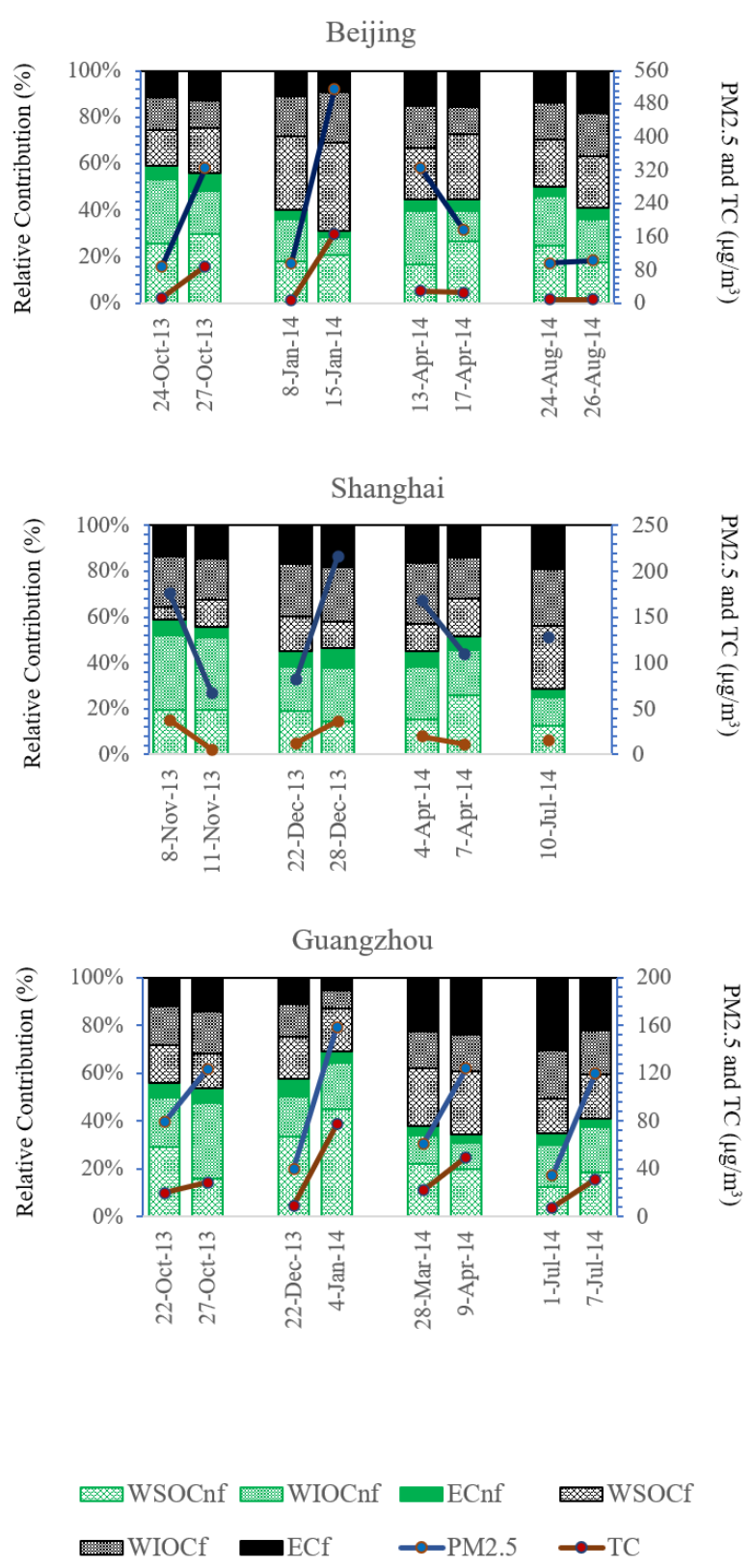

Fig. 3. The relative contributions of fossil $\mathrm{EC}\left(\mathrm{EC}_{\mathrm{f}}\right)$, fossil water-insoluble $\mathrm{OC}\left(\mathrm{WIOC}_{\mathrm{f}}\right)$, fossil water-soluble $\mathrm{OC}$ $\left(\mathrm{WSOC}_{\mathrm{f}}\right)$, non-fossil $\mathrm{EC}\left(\mathrm{EC}_{\mathrm{nf}}=\mathrm{EC}_{\mathrm{bb}}\right)$, non-fossil waterinsoluble OC $\left(\mathrm{WIOC}_{\mathrm{nf}}\right)$, and non-fossil water-soluble OC $\left(\mathrm{WSOC}_{\mathrm{nf}}\right)$ to total carbon (TC) and the concentrations of $\mathrm{PM}_{2.5}$ and $\mathrm{TC}$ in four seasons (autumn/Au, winter/Wi, spring/Sp, summer/Su) in Beijing, Shanghai and Guangzhou.

Shanghai, and Guangzhou, respectively. Non-fossil source was also an important contributor $(45 \%, 46 \%$, and $48 \%$ for Beijing, Shanghai, and Guangzhou, respectively). Seasonally, in Beijing and Guangzhou, the source compositions were generally consistent during spring and summer, but the average contribution of NF sources in Beijing ( $45 \pm 4 \%)$ was higher than that in Guangzhou (37 $\pm 3 \%)$. The results of 3-day back trajectory analysis indicated that natural and biogenic emissions from upwind rural and mountainous areas strongly impacted the air quality in Beijing, whereas the major carbon sources in Guangzhou were from vehicle and industrial emissions in the Pearl River Delta region. In Shanghai, the carbon source composition during spring was most similar to that during winter, but a dramatic increase in FF-derived carbon was observed during summer. The limited sample numbers during summer in Shanghai might have led to biased results. On the other hand, a recent study indicated that the greatest ratio of primary ship-emitted particles to total particles in the Shanghai urban region could reach 50\% during ship plume cases, which usually occur during spring and summer (Liu et al., 2017b). The corresponding back trajectory showed that the air mass came from the East China Sea and passed over the eastern coast of China. In addition to pollutants from industrial and vehicle emissions, the contribution of emissions from fishing boats and large ships near the air sampling site in Shanghai cannot be ignored.

Above all, this study demonstrated that the main sources of carbonaceous aerosols in cities vary greatly among seasons. In Beijing, the seasonal variation was similar to variations in submicrometric organic aerosols measured from 2013 to 2014, with fossil fuel source enhancement in winter (Zhang et al., 2017). Table 3 lists the ${ }^{14} \mathrm{C}$ results from $\mathrm{PM}_{2.5}$ in three cities during 2012-2014 published in previous studies. Compared with previous studies, the seasonal variations of carbon sources in the three cities were highly consistent with previous observations conducted in different seasons (Liu et al., 2014, 2016; Liu et al., 2017c; Liu et al., 2018). The carbon sources from OC and EC of high- $\mathrm{PM}_{2.5}$ samples and low- $\mathrm{PM}_{2.5}$ samples from each season were nearly consistent in this study (Fig. 3). Due to the limited data, these results might not reflect the true source variation over a 1-year period. For example, carbon source dynamics of carbonaceous aerosols during haze formation in Guangzhou indicated that there are significant differences in the carbon sources of high-PM $\mathrm{P}_{2.5}$ samples and low- $\mathrm{PM}_{2.5}$ samples during spring and summer (Liu et al., 2016, 2018). In addition, carbon sources of the high- $\mathrm{PM}_{2.5}$ samples in Guangzhou winter also differ from each other (Liu et al., 2014). In those previous studies, variation of the carbon source of atmospheric aerosols is often affected by changes in meteorological conditions, such as wind direction and speed. In this study, the air masses of the high- $\mathrm{PM}_{2.5}$ and low- $\mathrm{PM}_{2.5}$ samples during each season and at each site originated from approximately the same direction (Fig. 1), following the average wind direction of this season. Thus, the results of this study may reflect regional pollution characteristics during different seasons in each city.

\section{Possible Sources of Secondary Organic Aerosols}

Based on water solubility, OC was separated into WSOC and WIOC. EC and WIOC were generally considered primary emissions, whereas WSOC was a proxy for secondary OC (SOC) and BB OC (Zhang et al., 2017). Previous studies have indicated that SOC is the predominant component of WSOC in cities (Huang et al., 2014; Liu et al., 2016). In this study, WSOC accounted for $47 \pm 7 \%, 32 \pm 7 \%$, and $43 \pm$ $12 \%$ of TC in Beijing, Shanghai, and Guangzhou, respectively, and was significantly positively correlated with $\mathrm{PM}_{2.5}$ concentrations, showing the importance of WSOC in 
Table 3. Fossil fuel fraction of TC and EC in $\mathrm{PM}_{2.5}$ during 2012-2014 in three cities.

\begin{tabular}{|c|c|c|c|c|c|c|c|}
\hline \multirow{2}{*}{ Site/Time } & \multicolumn{2}{|c|}{ Beijing } & \multicolumn{2}{|c|}{ Shanghai } & \multicolumn{2}{|c|}{ Guangzhou } & \multirow{2}{*}{ Ref. } \\
\hline & $\mathrm{TC}$ & $\mathrm{EC}$ & $\mathrm{TC}$ & EC & TC & $\mathrm{EC}$ & \\
\hline Jan-2013(H) & & $74 \%$ & & $68 \%$ & & $68 \%$ & (Andersson et al., 2015) \\
\hline Jan-13(L) & $49 \%$ & & $43 \%$ & & $22 \%$ & & (Huang et al., 2014) \\
\hline Jan-13(H) & $60 \%$ & & $46 \%$ & & $36 \%$ & & \\
\hline Jan-13(H) & & & & & $53 \%$ & $86 \%$ & (Liu et al., 2014) \\
\hline Jan-13(H) & & & & & $36 \%$ & $66 \%$ & \\
\hline Jan-13(L) & & & & & $40 \%$ & $66 \%$ & \\
\hline Jan-13(H) & & & & $69 \%$ & & & (Wei et al., 2017) \\
\hline Mar-Apr, 2013(A) & $44 \%$ & $67 \%$ & & & $54 \%$ & $80 \%$ & (Liu et al., 2016) \\
\hline Jul-13(H) & & & & & $32 \%$ & $76 \%$ & (Liu et al., 2018) \\
\hline Jul-13(L) & & & & & $60 \%$ & $86 \%$ & \\
\hline Oct-Nov-13(H) & $37 \%$ & $51 \%$ & $33 \%$ & $67 \%$ & $29 \%$ & $51 \%$ & (Liu et al., 2017a) \\
\hline Oct-Nov-13(L) & $30 \%$ & $49 \%$ & $29 \%$ & $44 \%$ & $41 \%$ & $76 \%$ & \\
\hline
\end{tabular}

Note. $\mathrm{H}$ means higher $\mathrm{PM}_{2.5}$ concentration, L means lower $\mathrm{PM}_{2.5}$, A means average levels.

megacities. This finding suggests that SOC plays an important role in high-PM $\mathrm{P}_{2.5}$ events in Beijing and Guangzhou. It should also be noted that formation of secondary organic aerosol (SOA) derived from biogenic VOCs may have contributed to WSOC fraction in the three cities during the summer season.

The potential major sources of WSOC may be revealed by plotting our data. As shown in Fig. 4(A), the percentage of non-fossil WSOC to TC was positively correlated with the ratio of $\mathrm{EC}_{\mathrm{bb}} / \mathrm{EC}$. $\mathrm{EC}$ is exclusively of primary origin and is emitted from incomplete combustion of FFs and BB. This correlation indicates that the increase in non-fossil WSOC is likely due to enhanced BB. On one hand, a large fraction of the POC from BB is water soluble; on the other hand, increased emission of volatile organic compounds during BB could lead to an increase in NF secondary organic aerosols. This suggests that BB emissions have an important impact on non-fossil SOC in China. Recently, evidence from an SOA tracer indicated that a large nationwide increase in secondary organic aerosols during the cold season was highly associated with an increase in BB emissions (Ding et al., 2017). In principle, fresh POC emitted from FF combustion is water insoluble. A previous study evaluated the differences in WSOC levels at sites with no direct influence from vehicle exhaust emissions and concluded that very little primary WSOC is emitted directly from vehicles (Weber et al., 2007). Regarding another type of FF, only $\sim 1 \%$ of coal-sourced fresh OC is water soluble (Park et al., 2012). Thus, POC derived from FF combustion can reasonably be considered water insoluble, and fossil WSOC is used to estimate the levels of FF-derived SOC (Weber et al., 2007). The fossil WSOC/TC ratio versus the $\mathrm{WIOC}_{\mathrm{f}} / \mathrm{EC}_{\mathrm{f}}$ ratio is plotted in Fig. 4(B). The primary sources of $\mathrm{WIOC}_{\mathrm{f}}$ and $\mathrm{EC}_{\mathrm{f}}$ were coal combustion and emissions from internal combustion engines fueled by petroleum. Generally, the $\mathrm{WIOC}_{\mathrm{f}} / \mathrm{EC}_{\mathrm{f}}$ ratio from coal combustion was higher than that from vehicle emissions (Liu et al., 2013). As shown in Fig. 4(B), the proportion of $\mathrm{WSOC}_{\mathrm{f}}$ decreased with increasing $\mathrm{WIOC}_{\mathrm{f}} / \mathrm{EC}_{\mathrm{f}}$ ratios in Shanghai and Guangzhou, indicating that fossil fuel SOC did not originate mainly from coal combustion sources, but rather from vehicle and ship emissions
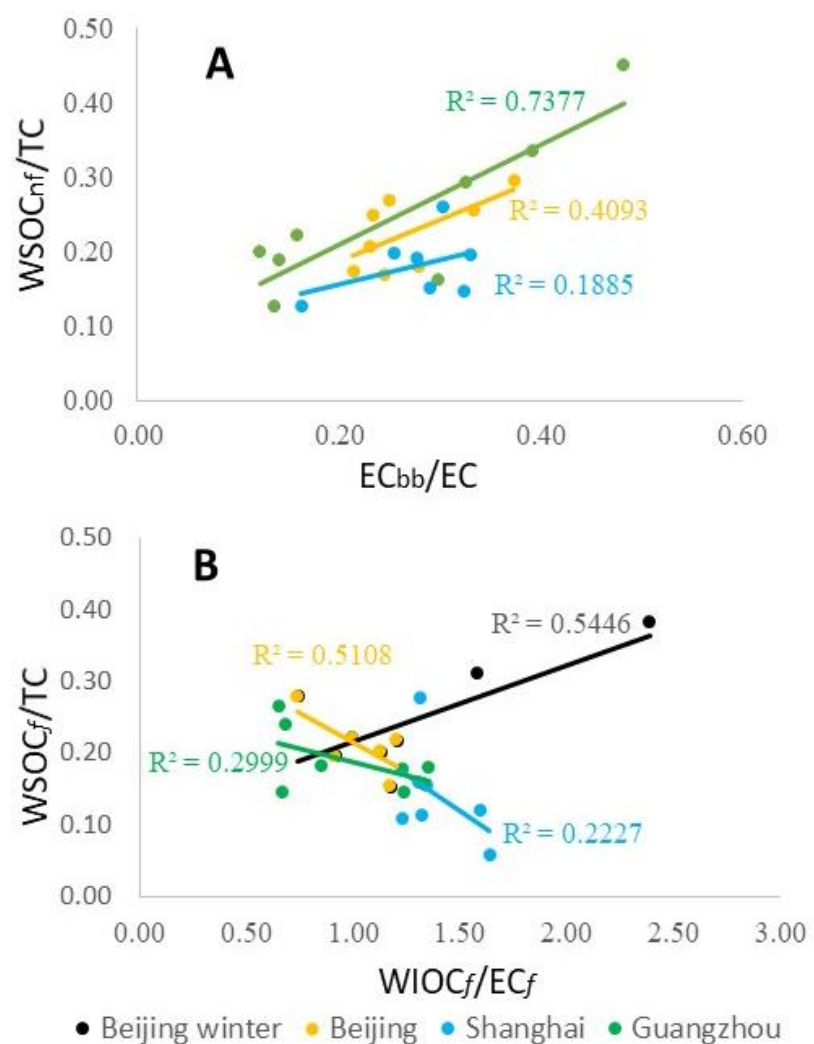

Fig. 4. Correlations of (A) $\mathrm{WSOC}_{\mathrm{nf}} / \mathrm{TC}$ vs. $\mathrm{EC}_{\mathrm{bb}} / \mathrm{EC}$, and (B) $\mathrm{WSOC}_{\mathrm{f}} / \mathrm{TC}$ vs. $\mathrm{WIOC}_{\mathrm{f}} / \mathrm{EC}_{\mathrm{f}}$. Beijing winter (black color) means all samples collected in Beijing; Beijing (yellow color) means winter samples were excluded.

or VOCs released from industrial sources. However, the trend differed in Beijing. Excluding winter samples, the pattern in Beijing was similar to those in Shanghai and Guangzhou, but the trend shifted to the opposite of those in Shanghai and Guangzhou when the winter samples were included. These results suggest that the fossil fuel SOC in Beijing is sourced mainly from residential coal combustion during winter and from vehicle exhaust or industrial emissions during other seasons. 


\section{CONCLUSION}

This study conducted source apportionment of the carbonaceous aerosol in three megacities in China across four seasons. The ${ }^{14} \mathrm{C}$ content in four carbonaceous fractions of $\mathrm{PM}_{2.5}$, viz., EC, OC, WSOC, and WIOC, was measured. The carbonaceous aerosol accounted for $20 \pm 6 \%, 17 \pm 6 \%$, and $36 \pm 8 \%$ of the $\mathrm{PM}_{2.5}$ mass in Beijing, Shanghai, and Guangzhou, respectively. The $\mathrm{PM}_{2.5}$, OC, and EC exhibited higher mass concentrations during winter and lower ones during summer. Based on the ${ }^{14} \mathrm{C}$ measurements, the average annual contributions of $\mathrm{FF}$ and NF to the TC were almost equal, with FF:NF ratios of 54:46, 53:47, and 52:48 in Beijing, Shanghai, and Guangzhou, respectively. Emissions arising from FF combustion dominated the EC (> 72\%), whereas those derived from NF accounted for a slightly higher proportion of the OC (50-55\%). Additionally, NF generated the primary share $(>55 \%)$ in all of the cities during autumn. FF emissions constituted the majority of the carbonaceous pollution (64\%) in Beijing during winter, probably as a result of increased coal combustion for heating, and also played a greater role than NF in both Beijing $(\sim 55 \%)$ and Guangzhou ( $63 \%)$ during spring and summer. The higher contribution of NF in Beijing compared to Guangzhou may be due to heavy biogenic emissions from upwind rural and mountainous areas, which degraded the air quality in Beijing. Based on our limited number of samples, $71 \%$ of the carbonaceous aerosol in Shanghai during summer was attributable to FF, with a significant portion due to combustion (i.e., industrial, vehicular, fishing-boat, and large-vessel emissions). The secondary organic carbon mainly originated from biomass burning and vehicular emission, except in Beijing during winter, when residential coal combustion became the major source.

\section{ACKNOWLEDGEMENTS}

This work is funded by the National Key R\&D Program of China (2017YFC0212000), Natural Science Foundation of China (NSFC; Grant No. 41977177), Guangdong Foundation for Program of Science and Technology Research (Grant No. 2017B030314057), and State Key Laboratory of Organic Geochemistry (GIGCAS; Grant No. SKLOG 2020-5). All data in this manuscript are freely available upon request through the corresponding author (junli@gig.ac.cn).

\section{SUPPLEMENTARY MATERIAL}

Supplementary data associated with this article can be found in the online version at https://doi.org/10.4209/aaqr.2 019.12.0642

\section{REFERENCES}

Agrios, K., Salazar, G., Zhang, Y.L., Uglietti, C., Battaglia, M., Luginbühl, M., Ciobanu, V.G., Vonwiller, M. and Szidat, S. (2015). Online coupling of pure $\mathrm{O}_{2}$ thermo-optical methods${ }^{14} \mathrm{C}$ AMS for source apportionment of carbonaceous aerosols. Nucl. Instrum. Methods Phys. Res., Sect. B 361:
288-293. https://doi.org/10.1016/j.nimb.2015.06.008

Andersson, A., Deng, J., Du, K., Zheng, M., Yan, C., Sköld, M. and Gustafsson, O. (2015). Regionally-varying combustion sources of the January 2013 severe haze events over eastern China. Environ. Sci. Technol. 49: 2038-2043. https://doi.org/10.1021/es503855e

Bernardoni, V., Calzolai, G., Chiari, M., Fedi, M., Lucarelli, F., Nava, S., Piazzalunga, A., Riccobono, F., Taccetti, F., Valli, G. and Vecchi, R. (2013). Radiocarbon analysis on organic and elemental carbon in aerosol samples and source apportionment at an urban site in northern Italy. $J$. Aerosol Sci. 56: 88-99. https://doi.org/10.1016/j.jaerosci. 2012.06.001

Cao, J.J., Lee, S.C., Chow, J.C., Watson, J.G., Ho, K.F., Zhang, R.J., Jin, Z.D., Shen, Z.X., Chen, G.C., Kang, Y.M., Zou, S.C., Zhang, L.Z., Qi, S.H., Dai, M.H., Cheng, Y. and Hu, K. (2007). Spatial and seasonal distributions of carbonaceous aerosols over China. J. Geophys. Res. 112: D22S11. https://doi.org/10.1029/2006JD008205

Castro, L.M., Pio, C.A., Harrison, R.M. and Smith, D.J.T. (1999). Carbonaceous aerosol in urban and rural european atmospheres: Estimation of secondary organic carbon concentrations. Atmos. Environ. 33: 2771-2781. https://doi.org/10.1016/S1352-2310(98)00331-8

Cheng, Y., Zhen, M., He, K.B., Chen, Y., Yan, B., Russell, A.G., Shi, W., Jiao, Z., Sheng, G., Fu, J. and Edgerton, E.S. (2011). Comparison of two thermal-optical methods for the determination of organic carbon and elemental carbon: Results from the southeastern united states. Atmos. Environ. 45: 1913-1918. https://doi.org/10.1016/ j.atmosenv.2011.01.036

Chow, J.C., Watson, J.G., Pritchett, L.C., Pierson, W.R., Frazier, C.A. and Purcell, R.G. (1993). The dri thermal/optical reflectance carbon analysis system: description, evaluation and applications in U.S. Air quality studies. Atmos. Environ. 27: 1185-1201. https://doi.org/ 10.1016/0960-1686(93)90245-T

Ding, X., Zhang, Y.Q., He, Q.F., Yu, Q.Q., Shen, R.Q., Zhang, Y., Zhang, Z., Lyu, S.J., Wang, Y.S., Li, L.F., Song, W. and Wang, X.M. (2016). Spatial and seasonal variations of secondary organic aerosol from terpenoids over China. J. Geophys. Res. 121: 14661-14678. https://doi.org/10.1002/2016JD025467

Ding, X., Zhang, Y.Q., He, Q.F., Yu, Q.Q., Wang, J.Q., Shen, R.Q., Song, W., Wang, Y.S. and Wang, X.M. (2017). Significant increase of aromatics-derived secondary organic aerosol during fall to winter in China. Environ. Sci. Technol. 51: 7432-7441. https://doi.org/10.1021/acs.est.6b06408

Dusek, U., Hitzenberger, R., Kasper-Giebl, A., Kistler, M., Meijer, H.A., Szidat, S., Wacker, L., Holzinger, R. and Röckmann, T. (2017). Sources and formation mechanisms of carbonaceous aerosol at a regional background site in the Netherlands: Insights from a year-long radiocarbon study. Atmos. Chem. Phys. 17: 3233-3251. https://doi.org/ 10.5194/acp-17-3233-2017

Elser, M., Huang, R.J., Wolf, R., Slowik, J.G., Wang, Q., Canonaco, F., Li, G., Bozzetti, C., Daellenbach, K.R., Huang, Y., Zhang, R., Li, Z., Cao, J., Baltensperger, U., El-Haddad, I. and Prevot, A.S.H. (2016). New Insights 
into $\mathrm{PM}_{2.5}$ chemical composition and sources in two major cities in China during extreme haze events using aerosol mass spectrometry. Atmos. Chem. Phys. 16: 3207-3225. https://doi.org/10.5194/acp-16-3207-2016

Feng, J.L., Hu, J.C., Xu, B.H., Hu, X.L., Sun, P., Han, W.L., Gu, Z.P., Yu, X.M. and Wu, M.H. (2015). Characteristics and seasonal variation of organic matter in $\mathrm{PM}_{2.5}$ at a regional background site of the yangtze river delta region, China. Atmos. Environ. 123: 288-297. https://doi.org/10. 1016/j.atmosenv.2015.08.019

He, L.Y., Hu, M., Zhang, Y.H., Huang, X.F. and Yao, T.T. (2008). Fine particle emissions from on-road vehicles in the Zhujiang tunnel, China. Environ. Sci. Technol. 42: 4461-4466. https://doi.org/10.1021/es7022658

Highwood, E.J. and Kinnersley, R.P. (2006). When smoke gets on our eyes: The multiple impacts of atmospheric black carbon on climate, air quality and health. Environ. Int. 32: 560-566. https://doi.org/10.1016/j.envint.2005.1 2.003

Hu, J., Wang, Y., Ying, Q. and Zhang, H. (2014). Spatial and temporal variability of $\mathrm{PM}_{2.5}$ and $\mathrm{PM}_{10}$ over the North China Plain and the Yangtze River Delta, China. Atmos. Environ. 95: 598-609. https://doi.org/10.1016/j.atmosen v.2014.07.019

Huang, R.J., Zhang, Y., Bozzetti, C., Ho, K.F., Cao, J.J., Han, Y., Daellenbach, K.R., Slowik, J.G., Platt, S.M., Canonaco, F., Zotter, P., Wolf, R., Pieber, S.M., Bruns, E.A., Crippa, M., Ciarelli, G., Piazzalunga, A., Schwikowski, M., Abbaszade, G., ... Prevot, A.S.H. (2014). High secondary aerosol contribution to particulate pollution during haze events in China. Nature 514: 218-222. https://doi.org/10.1038/nature13774

Jiang, H., Zhong, G., Wang, J., Jiang, H., Tian, C., Li, J., Zhao, S., Yu, Z., Morawska, L. and Zhang, G. (2018). Using polyurethane foam-based passive air sampling technique to monitor monosaccharides at a regional scale. Environ. Sci. Technol. 52: 12546-12555. https://doi.org/ 10.1021/acs.est.8b02254

Khan, M.F., Shirasuna, Y., Hirano, K. and Masunaga, S. (2010). Characterization of $\mathrm{PM}_{2.5}, \mathrm{PM}_{2.5-10}$ and $\mathrm{PM}_{>10}$ in ambient air, Yokohama, Japan. Atmos. Res. 96: 159-172. https://doi.org/10.1016/j.atmosres.2009.12.009

Kim, H.S., Huh, J.B., Hopke, P.K., Holsen, T.M. and Yi, S.M. (2007). Characteristics of the major chemical constituents of $\mathrm{PM}_{2.5}$ and smog events in Seoul, Korea in 2003 and 2004. Atmos. Environ. 41: 6762-6770. https://doi.org/10.1016/j.atmosenv.2007.04.060

Ling, Z.H., Guo, H., Cheng, H.R. and Yu, Y.F. (2011). Sources of ambient volatile organic compounds and their contributions to photochemical ozone formation at a site in the Pearl River Delta, southern China. Environ. Pollut. 159: 2310-2319. https://doi.org/10.1016/j.envpol.2011.0 5.001

Liu, D., Li, J., Zhang, Y., Xu, Y., Liu, X., Ding, P., Shen, C., Chen, Y., Tian, C. and Zhang, G. (2013). The use of levoglucosan and radiocarbon for source apportionment of $\mathrm{PM}_{2.5}$ carbonaceous aerosols at a background site in east China. Environ. Sci. Technol. 47: 10454-10461. https://doi.org/10.1021/es401250k
Liu, D., Li, J., Cheng, Z., Zhong, G., Zhu, S., Ding, P., Shen, C., Tian, C., Chen, Y., Zhi, G. and Zhang, G. (2017a). Sources of non-fossil-fuel emissions in carbonaceous aerosols during early winter in Chinese cities. Atmos. Chem. Phys. 17: 11491-11502. https://doi.org/10.5194/a cp-17-11491-2017

Liu, J., Li, J., Zhang, Y., Liu, D., Ding, P., Shen, C., Shen, K., He, Q., Ding, X., Wang, X. and Chen, D., Szidat, S. and Zhang, G. (2014). Source apportionment using radiocarbon and organic tracers for $\mathrm{PM}_{2.5}$ carbonaceous aerosols in guangzhou, south China: Contrasting localand regional-scale haze events. Environ. Sci. Technol. 48: 12002-12011. https://doi.org/10.1021/es503102w

Liu, J., Li, J., Liu, D., Ding, P., Shen, C., Mo, Y., Wang, X., Luo, C., Cheng, Z., Szidat, S., Zhang, Y., Chen, Y. and Zhang, G. (2016). Source apportionment and dynamic changes of carbonaceous aerosols during the haze bloomdecay process in China based on radiocarbon and organic molecular tracers. Atmos. Chem. Phys. 16: 2985-2996. https://doi.org/10.5194/acp-16-2985-2016

Liu, J., Li, J., Ding, P., Zhang, Y., Liu, D., Shen, C. and Zhang, G. (2017b). Optimizing isolation protocol of organic carbon and elemental carbon for ${ }^{14} \mathrm{C}$ analysis using fine particulate samples. Atmos. Environ. 154: 919. https://doi.org/10.1016/j.atmosenv.2017.01.027

Liu, J., Ding, P., Zong, Z., Li, J., Tian, C., Chen, W., Chang, M., Salazar, G., Shen, C., Cheng, Z., Chen, Y., Wang, X., Szidat, S. and Zhang, G. (2018). Evidence of Rural and Suburban Sources of Urban Haze Formation in China: A Case Study From the Pearl River Delta Region. J. Geophys. Res. 123: 4712-4726. https://doi.org/10.1029/2 017JD027952

Liu, P., Zhang, C., Xue, C., Mu, Y., Liu, J., Zhang, Y., Tian, D., Ye, C., Zhang, H. and Guan, J. (2017c). The contribution of residential coal combustion to atmospheric $\mathrm{PM}_{2.5}$ in northern China during winter. Atmos. Chem. Phys. 17: 11503-11520. https://doi.org/10.5194/acp-1711503-2017

Mauderly, J.L. and Chow, J.C. (2008). Health effects of organic aerosols. Inhalation Toxicol. 20: 257-288. https://doi.org/10.1080/08958370701866008

Miyakawa, T., Komazaki, Y., Zhu, C., Taketani, F., Pan, X., Wang, Z. and Kanaya, Y. (2019). Characterization of carbonaceous aerosols in Asian outflow in the spring of 2015: Importance of non-fossil fuel sources. Atmos. Environ. 214: 116858. https://doi.org/10.1016/j.atmosen v. 2019.116858

Miyazaki, Y., Kondo, Y., Takegawa, N., Komazaki, Y., Fukuda, M., Kawamura, K., Mochida, M., Okuzawa, K. and Weber, R.J. (2006). Time-resolved measurements of water-soluble organic carbon in Tokyo. J. Geophys. Res. 111: D23206. https://doi.org/10.1029/2006JD007125

Paraskevopoulou, D., Liakakou, E., Gerasopoulos, E., Theodosi, C. and Mihalopoulos, N. (2014). Long-term characterization of organic and elemental carbon in the $\mathrm{PM}_{2.5}$ fraction: The case of Athens, Greece. Atmos. Chem. Phys. 14: 13313-13325. https://doi.org/10.5194/acp-1413313-2014

Park, S.S., Jeong, J.U. and Cho, S.Y. (2012). Group 
separation of water-soluble organic carbon fractions in ash samples from a coal combustion boiler. Asian $J$. Atmos. Environ. 6: 67-72. http:/dx.doi.org/10.5572/ajae. 2012.6.1.067

Perrone, M.R., Piazzalunga, A., Prato, M. and Carofalo, I. (2011). Composition of fine and coarse particles in a coastal site of the central mediterranean: Carbonaceous species contributions. Atmos. Environ. 45: 7470-7477. https://doi.org/10.1016/j.atmosenv.2011.04.030

Pöschl, U. (2005). Atmospheric aerosols: Composition, transformation, climate and health effects. Angew. Chem. Int. Ed. 44: 7520-7540. https://doi.org/10.1002/anie.200 501122

Pratsinis, S., Ellis, E.C., Novakov, T. and Friedlander, S.K. (1984). The carbon containing component of the los angeles aerosol: Source apportionment and contributions to the visibility budget. J. Air Pollut. Control Assoc. 34: 643650. https://doi.org/10.1080/00022470.1984.10465792

Schauer, J.J., Kleeman, M.J., Cass, G.R. and Simoneit, B.R.T. (1999). Measurement of emissions from air pollution sources. 2. $\mathrm{C}_{1}$ through $\mathrm{C}_{30}$ organic compounds from medium duty diesel trucks. Environ. Sci. Technol. 33: 1578-1587. https://doi.org/10.1021/es980081n

Schauer, J.J., Kleeman, M.J., Cass, G.R. and Simoneit, B.R.T. (2001). Measurement of emissions from air pollution sources. 3. $\mathrm{C}_{1}-\mathrm{C}_{29}$ organic compounds from fireplace combustion of wood. Environ. Sci. Technol. 35: 1716-1728. https://doi.org/10.1021/es001331e

Schauer, J.J., Kleeman, M.J., Cass, G.R. and Simoneit, B.R.T. (2002). Measurement of emissions from air pollution sources. 5. $\mathrm{C}_{1}-\mathrm{C}_{32}$ organic compounds from gasoline-powered motor vehicles. Environ. Sci. Technol. 36: 1169-1180. https://doi.org/10.1021/es0108077

Stuiver, M. and Polach, HA. (1977). Discussion: Reporting of ${ }^{14} \mathrm{C}$ data. Radiocarbon 19: 355-63. https://doi.org/10.1 017/S0033822200003672

Szidat, S., Jenk, T.M., Gaggeler, H.W., Synal, H.A., Fisseha, R., Baltensperger, U., Kalberer, M., Samburova, V., Wacker, L. and Saurer, M. (2004). Source apportionment of aerosols by ${ }^{14} \mathrm{C}$ measurements in different carbonaceous particle fractions. Radiocarbon 46: 475-484. https://doi.org/10.1017/S0033822200039783

Szidat, S., Ruff, M., Perron, N., Wacker, L., Synal, H.A., Hallquist, M., Shannigrahi, A.S., Yttri, K.E., Dye, C. and Simpson, D. (2009). Fossil and non-fossil sources of organic carbon (OC) and elemental carbon (EC) in Göteborg, Sweden. Atmos. Chem. Phys. 9: 1521-1535. https://doi.org/10.5194/acp-9-1521-2009

Szidat, S., Salazar, G.A., Vogel, E., Battaglia, M., Wacker, L., Synal, H.A. and Türler, A. (2014). ${ }^{14} \mathrm{C}$ analysis and sample preparation at the new bern laboratory for the analysis of radiocarbon with AMS (LARA). Radiocarbon 56: 561-566. https://doi.org/10.2458/56.17457

Turpin, B.J. and Lim, H.J. (2001). Species contributions to $\mathrm{PM}_{2.5}$ mass concentrations: Revisiting common assumptions for estimating organic mass. Aerosol Sci. Technol. 35: 602-610. https://doi.org/10.1080/02786820152051454

Weber, R.J., Sullivan, A.P., Peltier, R.E., Russell, A., Yan, B., Zheng, M., de Gouw, J., Warneke, C., Brock, C.,
Holloway, J.S., Atlas, E.L. and Edgerton, E. (2007). A study of secondary organic aerosol formation in the anthropogenic-influenced southeastern United States. $J$. Geophys. Res. 112: D13302. https://doi.org/10.1029/200 7JD008408

Wei, N., Wang, G., Zhouga, D., Deng, K., Feng, J., Zhang, Y., Xiao, D. and Liu, W. (2017). Source apportionment of carbonaceous particulate matter during haze days in Shanghai based on the radiocarbon. J. Radioanal. Nucl. Chem. 313: 145-153. https://doi.org/10.1007/s10967017-5267-1

Xu, P., Zhang, J., Ji, D., Liu, Z., Tang, G., Jiang, C. and Wang, Y. (2018). Characterization of submicron particles during autumn in Beijing, China. J. Environ. Sci. 63: 1627. https://doi.org/10.1016/j.jes.2017.03.036

Zha, S., Zhang, S., Cheng, T., Chen, J., Huang, G., Li, X. and Wang, Q. (2013). Agricultural fires and their potential impacts on regional air quality over China. Aerosol Air Qual. Res. 13: 992-1001. https://doi.org/10.4209/aaqr.20 12.10.0277

Zhang, Y., Schauer, J.J., Zhang, Y., Zeng, L., Wei, Y., Liu, Y. and Shao, M. (2008). Characteristics of particulate carbon emissions from real-world Chinese coal combustion. Environ. Sci. Technol. 42: 5068-5073. https://doi.org/10. 1021/es7022576

Zhang, Y.L., Perron, N., Ciobanu, V.G., Zotter, P., Minguillón, M.C., Wacker, L., Prévôt, A.S.H., Baltensperger, U. and Szidat, S. (2012). On the isolation of OC and EC and the optimal strategy of radiocarbonbased source apportionment of carbonaceous aerosols. Atmos. Chem. Phys. 12: 10841-10856. https://doi.org/10. 5194/acp-12-10841-2012

Zhang, Y.L., Huang, R.J., El Haddad, I., Ho, K.F., Cao, J.J., Han, Y., Zotter, P., Bozzetti, C., Daellenbach, K.R., Canonaco, F., Slowik, J.G., Salazar, G., Schwikowski, M., Schnelle-Kreis, J., Abbaszade, G., Zimmermann, R., Baltensperger, U., Prévôt, A.S.H. and Szidat, S. (2015a). Fossil vs. non-fossil sources of fine carbonaceous aerosols in four Chinese cities during the extreme winter haze episode of 2013. Atmos. Chem. Phys.15: 12991312. https://doi.org/10.5194/acp-15-1299-2015

Zhang, Y.L., Schnelle-Kreis, J., Abbaszade, G., Zimmermann, R., Zotter, P., Shen, R.R., Schafer, K., Shao, L., Prevot, A.S.H. and Szidat, S. (2015b). Source apportionment of elemental carbon in Beijing, China: Insights from radiocarbon and organic marker measurements. Environ. Sci. Technol. 49: 8408-8415. https://doi.org/10.1021/acs. est.5b01944

Zhang, Y., Ren, H., Sun, Y., Cao, F., Chang, Y., Liu, S., Lee, X., Agrios, K., Kawamura, K., Liu, D., Ren, L., Du, W., Wang, Z., Prevot, A.S.H., Szida, S. and Fu, P. (2017). High contribution of nonfossil sources to submicrometer organic aerosols in Beijing, China. Environ. Sci. Technol. 51: 7842-7852. https://doi.org/10.1021/acs.est.7b01517

Zhang, Y.X., Shao, M., Zhang, Y.H., Zeng, L.M., He, L.Y., Zhu, B., Wei, Y.J. and Zhu, X.L. (2007). Source profiles of particulate organic matters emitted from cereal straw burnings. J. Environ. Sci. 19: 167-175. https://doi.org/10. 1016/S1001-0742(07)60027-8 
Zhi, G., Chen, Y., Feng, Y., Xiong, S., Li, J., Zhang, G., Sheng, G. and Fu, J. (2008). Emission characteristics of carbonaceous particles from various residential coalstoves in China. Environ. Sci. Technol. 42: 3310-3315. https://doi.org/10.1021/es702247q

Zhou, R., Wang, S., Shi, C., Wang, W., Zhao, H., Liu, R., Chen, L. and Zhou, B. (2014). Study on the traffic air pollution inside and outside a road tunnel in Shanghai, China. PLoS One 9: e112195. https://doi.org/10.1371/jou rnal.pone.0112195

Zong, Z., Wang, X., Tian, C., Chen, Y., Qu, L., Ji, L., Zhi,
G., Li, J. and Zhang, G. (2016). Source apportionment of $\mathrm{PM}_{2.5}$ at a regional background site in north China using PMF linked with radiocarbon analysis: Insight into the contribution of biomass burning. Atmos. Chem. Phys. 16: 11249-11265. https://doi.org/10.5194/acp-16-11249-2016

Received for review, December 20, 2019

Revised, June 2, 2020

Accepted, June 6, 2020 